\title{
Analisis Karakteristik dan Persepsi Pengguna Pelayanan Terhadap Pemanfaatan Puskesmas Sebagai Gatekeeper di Dua Puskesmas Kota Bekasi Tahun 2016
}

\section{Analysis of Characteristics and Perception of Services User towards Gatekeeper Utilization of Public Health Centers (PHC/Puskesmas) in two Puskesmas in Bekasi 2016}

\author{
Fitria Kusumawati Wulandari', Anhari Achadi ${ }^{2}$ \\ ${ }^{1}$ Program Studi Magister IImu Kesehatan Masyarakat Fakultas Kesehatan Masyarakat Universitas Indonesia, Depok \\ ${ }^{2}$ Departemen Administrasi Kebijakan Kesehatan, Fakultas Kesehatan Masyarakat, Universitas Indonesia, Depok \\ Korespondensi: Fitria Kusumawati Wulandari \\ e-mail: fitzghasani@gmail.com
}

\begin{abstract}
Abstrak
Konsep pelayanan kesehatan primer pada era Jaminan Kesehatan Nasional (JKN) dikembangkan dengan penguatan pelayanan primer sebagai gatekeeper dengan konsep managed care. Pada konsep managed care, suksesnya sistem gatekeeper salah satunya dinilai dari angka kunjungan dan angka rujukan ke Fasilitas Kesehatan Tingkat Lanjutan (FKTL). Penelitian ini bertujuan untuk mengetahui karakteristik dan persepsi pengguna pelayanan terhadap pemanfaatan Puskesmas sebagai gatekeeper di dua puskesmas Kota Bekasi. Penelitian ini menggunakan desain cross sectional dan pengumpulan data melalui pengisian kuesioner oleh 208 pasien peserta JKN di dua puskesmas Kota Bekasi dengan metode pengambilan sampel secara stratified purposive sampling. Hasil penelitian menunjukkan pekerjaan (nilai $p=0,018$ ), persepsi terhadap sikap petugas kesehatan (nilai $p=0,000$ ), dan lama berobat (nilai $p=0,048$ ) berhubungan dengan pemanfaatan puskesmas sebagai gatekeeper. Persepsi terhadap sikap petugas kesehatan merupakan faktor dominan yang mempengaruhi pemanfaatan Puskesmas sebagai gatekeeper $(r=0.720)$. Penerapan konsep gatekeeper dengan baik dapat meningkatkan pemanfaatan Puskesmas dan menekan angka rujukan ke FKTL.

Kata Kunci : Gatekeeper, Pemanfaatan Puskesmas, Persepsi terhadap Sikap Petugas Kesehatan
\end{abstract}

\begin{abstract}
The concept of primary health care in the era of National Health Insurance (JKN) is developed by strengthening primary health care as a gatekeeper with the concept of managed care. In this concept of managed care, one og the success story of the gatekeeper system is assessed by the visit and referral rates to the Higher Level of Health Facilities (ALHF/Fasilitas Kesehatan Tingkat Lanjut). This study aimed to determine the characteristics and perception of service users towards utilization of public health centers (PHC/Puskesmas) as gatekeeper in two PHC in City of Bekasi. This study used cross-sectional design and data collection by filling up questionnaires by 208 patients of JKN members in two health centers in Bekasi with stratified purposive sampling methods. The results showed that job ( $p=0.018$ ), perceptions of the health workers' attitudes ( $p=0.000)$, and treatment duration ( $p=0.048$ ) were related to the utilization of PHC as a gatekeeper. Perceptions of the health workers' attitude was the dominant factor affecting the utilization of PHC as a gatekeeper $(r=0.720)$. The health workers' attitude affected the repeated utilization services in PHC and its utilization as a gatekeeper, especially for continuum care. The proper application of gatekeeper concept should be able to increase the utilization of PHC and reduce the number of referrals to the Advanced Level of Health Facilities (ALHF).

Keywords: Gatekeeper, Utilization of Public Health Center, Perception of health workers
\end{abstract}

\section{Pendahuluan}

Deklarasi Alma Atta tahun 1978 merupakan tonggak utama dalam pengembangan konsep pelayanan kesehatan primer untuk mewujudkan health for all. Konsep pelayanan primer menjadi fokus kebijakan di banyak negara di dunia. Hal ini sebagai respon terhadap meningkatnya kesenjangan akses pelayanan kesehatan yang sangat jelas di banyak negara berkembang. Penguatan pelayanan kesehatan primer juga menjadi fokus utama World Health Organization (WHO) dalam "The 2008 Annual Report” yang menyatakan WHO mendorong negara berkembang untuk melakukan reformasi dalam rangka penguatan pelayanan kesehatan primer. Empat reformasi yang harus dilaksanakan semua negara yaitu reformasi Universal Coverage, penyediaan layanan, kebijakan publik, dan kepemimpinan. Dengan melakukan reformasi tersebut, sistem kesehatan nasional dapat menjadi lebih jelas, lebih efektif dan efisien (WHO, 2008).

Konsep pelayanan kesehatan primer sebagai gatekeeper dikembangkan oleh Primary Care Center John Hopkins University, meliputi 4 domain utama yaitu first contact care (fungsi kontak pertama), continuity care (fungsi koordinasi layanan), coordination care (fungsi koordinasi layanan) dan comprehensiveness care (fungsi comprehensif layanan) (Starfield, 
1994). Konsep ini diadopsi oleh Badan Penyelenggara Jaminan Sosial (BPJS) Kesehatan dan menjadi salah satu indikator performa BPJS yang tercantum dalam Buku Panduan Praktis Gate Keeper Concept BPJS Kesehatan.

Menurut Perpres No. 12 tahun 2013 tentang JKN, penyelenggaraan pelayanan kesehatan, baik rawat jalan maupun rawat inap harus dilakukan dengan sistem berjenjang melalui pelayanan kesehatan tingkat pertama (primer), pelayanan kesehatan tingkat kedua (sekunder) dan pelayanan kesehatan tingkat ketiga (tersier). Dalam hal ini seharusnya pasien dapat memasuki pelayanan kesehatan yang lebih tinggi melalui rekomendasi dari dokter di pelayanan kesehatan primer. Jika fungsi gatekeeper berjalan dengan baik maka hanya pasien yang benar-benar membutuhkan perawatan lanjutan yang dapat ditujuk ke Rumah Sakit (FKTL).

Dalam Permennkes 75/2014, Puskesmas sebagai salah satu pelayanan kesehatan primer menyelenggarakan upaya kesehatan masyarakat dan upaya kesehatan perorangan tingkat pertama, dengan mengutamakan upaya promotif dan preventif, untuk mencapai derajat kesehatan masyarakat yang setinggi-tingginya. Dalam pelaksanaan saat ini Pelayanan kesehatan di puskesmas lebih terfokus pada aspek kuratif (Muninjaya, 2014). Idealnya peran Puskesmas sebagai gatekeeper mampu menggeser paradigma sakit dimana puskesmas hanya sebagai penyedia pengobatan bagi orang sakit (kuratif) menjadi paradigma sehat. Oleh karena itu fungsi Puskesmas sebagai gatekeeper menjadi sangat penting sebagai kontak pertama dan penapis rujukan serta pada konsep gatekeeper tersebut juga meliputi upaya promotif, preventif, kuratif, dan rehabilitatif yang dilakukan secara menyeluruh (Starfield, 1994) (BPJS, 2014). Menurut beberapa penelitian, karakteristik dan persepsi pengguna pelayanan yang diduga berhubungan dengan pemanfaatan fungsi pelayanan primer sebagai gatekeeper antara lain umur, jenis kelamin, pendidikan, pekerjaan, persepsi sakit, penyakit kronis, sikap petugas kesehatan, dan lama berobat (pelayanan kesehatan yang biasa dikunjungi) (Lee, et al. 2009, Wong, et al., 2010, Tsai et al., 2010, Yang et al., 2012, Saurina et al.,2012).

Berdasarkan data BPJS Kesehatan Kota Bekasi didapatkan rasio rujukan cukup tinggi yaitu 20\% untuk klinik dan 31\% untuk puskesmas. Grafik 1 menunjukkan rate kunjungan terendah di puskesmas-puskesmas Kota Bekasi yang masih di bawah zona aman $(<150$ per mil), sedangkan Grafik 2 menunjukkan rasio rujukan di Puskesmas Kota Bekasi masih cukup tinggi, yakni di atas angka rujukan ideal yang ditetapkan BPJS (15\%). Hal ini menunjukkan fungsi gatekeeper di puskesmas belum berjalan optimal. Oleh karena itu, penelitian ini bertujuan untuk mengetahui karakteristik dan persepsi pengguna pelayanan terhadap pemanfaatan Puskesmas sebagai gatekeeper di dua Puskesmas Kota Bekasi Tahun 2016.

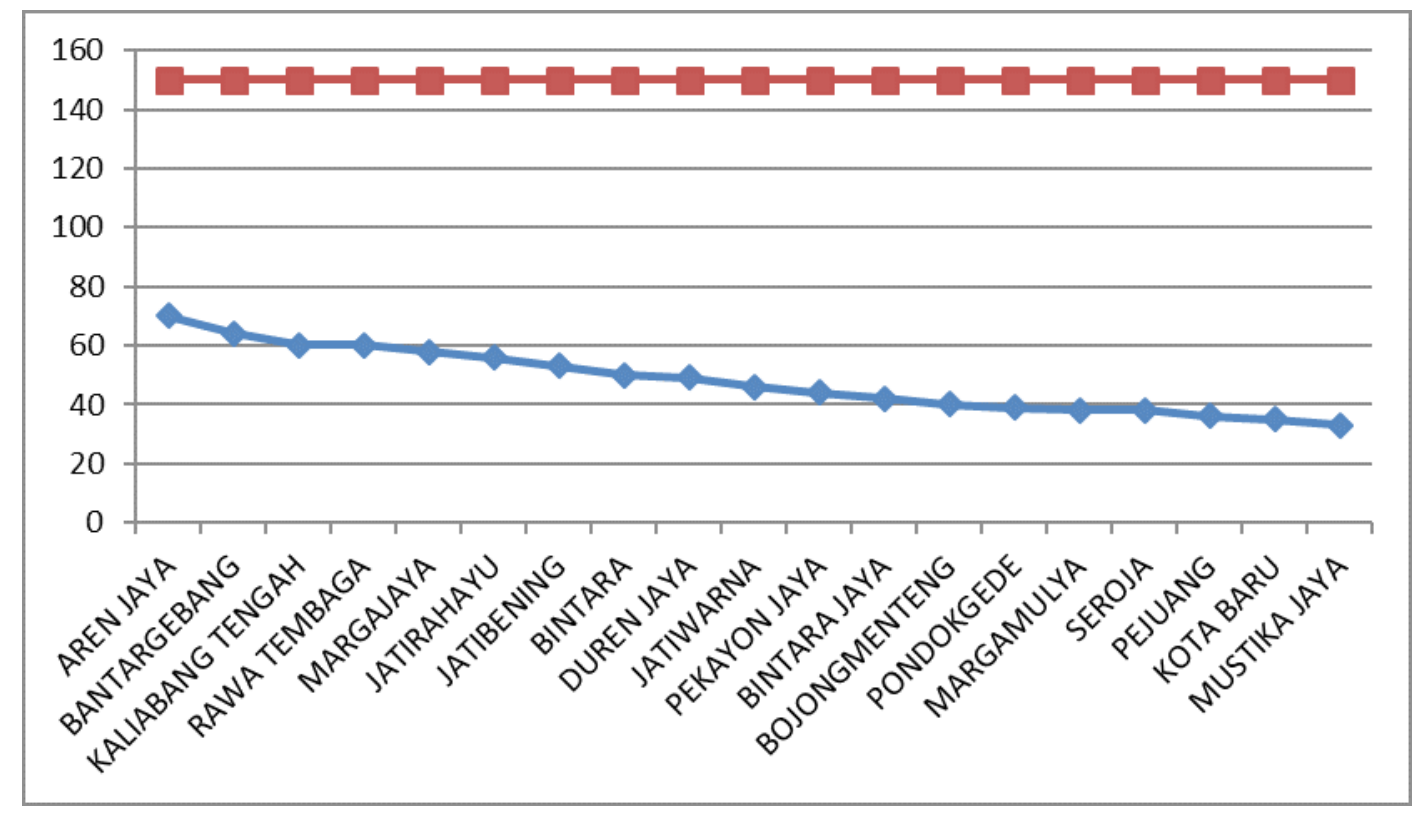

Grafik 1. 20 Puskesmas dengan Rate Kunjungan Terendah di Kota Bekasi 


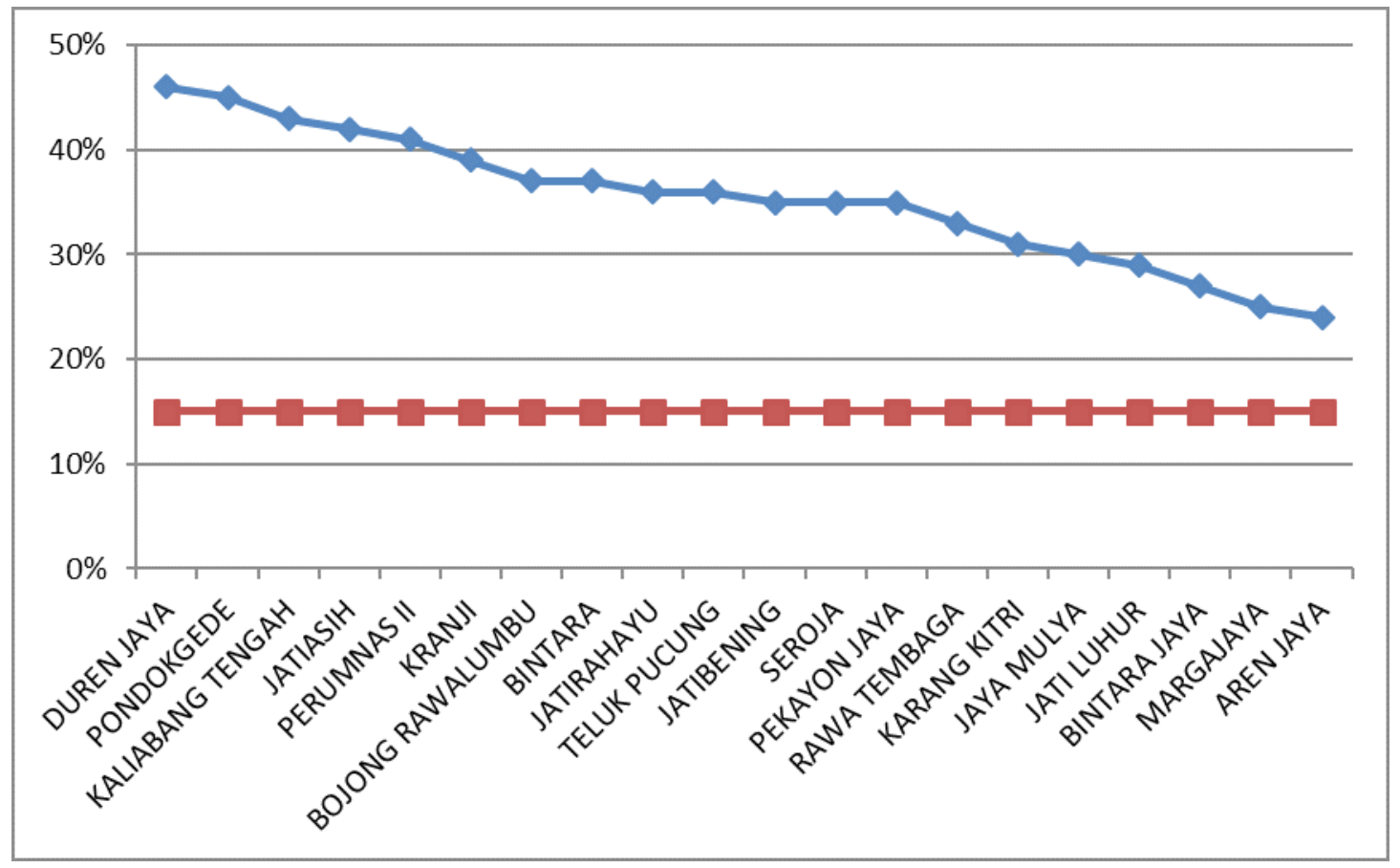

Grafik 2. 20 Puskesmas dengan Rasio Rujukan Tertinggi di Kota Bekasi

\section{Metode Penelitian}

Penelitian ini adalah penelitian kuantitatif dengan desain studi cross sectional. Sampel penelitian adalah sebagian pasien peserta JKN di dua Puskesmas Kota Bekasi dengan kriteria inklusi pasien berumur lebih dari 18 tahun dan kriteria eksklusi adalah pasien dengan kondisi gawat dan komplikasi berat. Jumlah sampel yang diambil sebesar 208 orang dengan menggunakan rumus estimasi rata-rata (mean) dengan tingkat kepercayaan 95\%. Metode yang digunakan dalam pengambilan sampel adalah dengan stratified purposive sampling dikarenakan sampel diambil dari populasi dengan beberapa strata yaitu puskesmas dengan rujukan tertinggi dan puskesmas dengan rujukan terendah berdasarkan data BPJS Bekasi.

Variabel dependen dalam studi ini adalah pemanfaatan puskesmas sebagai gatekeeper, sedangkan variabel independennya adalah faktor demografik (umur, jenis kelamin, pendidikan, pekerjaan), karakteristik kebutuhan (persepsi sakit dan penyakit kronis), faktor provider yaitu persepsi terhadap sikap petugas kesehatan dan lama berobat. Variabel pendidikan diukur berdasarkan lama waktu yang dihabiskan untuk mencapai jenjang tersebut, variabel persepsi sakit diukur berdasarkan jumlah keluhan gangguan kesehatan, dan variabel lama berobat berubah diukur dari durasi pasien (bulan) sejak pertama kali berobat ke puskesmas.

Data yang digunakan dalam penelitian ini adalah data primer dari hasil pengisian kuesioner yang digunakan untuk mengukur pemanfaatan puskesmas sebagai gatekeeper. Instrumen ini merupakan adaptasi dari Primary Care Assessment Tool (PCAT) (Shi, 2003) yang terdiri dari 19 pertanyaan dengan 4 pilihan jawaban. Pemanfaatan puskesmas dinilai berdasarkan fungsi kontak pertama (first contact care), kontinuitas layanan (continuity care), koordinasi layanan (coordination care), dan layanan komprehensif (comprehensiveness care). Variabel persepsi terhadap sikap petugas kesehatan mengadopsi kuesioner Yustianto (2009) yang disadur dari dimensi SERVQUAL oleh Parasuraman et al (1988). Kuesioner tersebut sebelumnya sudah diuji validitas dan reabilitasnya pada 30 pasien di Puskesmas Jati Mulya Kabupaten Bekasi yang memiliki karakteristik serupa dengan lokasi penelitian. Data dianalisis secara univariat, bivariat dengan regresi linier sederhana dan multivariat menggunakan regresi linier ganda.

\section{Hasil Penelitian}

Kuesioner yang terkumpul dalam penelitian ini berjumlah 208 dan semuanya valid untuk digunakan dalam penelitian ini. Rata-rata skor pemanfaatan Puskesmas sebagai gatekeeper sebesar 52.25 (Tabel 1). Berdasarkan tabel 2 pengguna pelayanan di dua Puskesmas Kota Bekasi didominasi oleh perempuan (65.4\%) dan mereka yang tidak bekerja (65.9\%). Gambaran per domain pemanfaatan Puskesmas sebagai gatekeeper dapat diuraikan pada tabel 3 . 
Tabel 1 Karakteristik dan Persepsi Pengguna Pelayanan terhadap Pemanfaatan Puskesmas sebagai Gatekeeper di Dua Puskesmas Kota Bekasi Tahun 2016

\begin{tabular}{|c|c|c|c|c|c|}
\hline \multicolumn{2}{|c|}{ Variabel } & \multirow{2}{*}{$\begin{array}{l}\text { Mean } \\
52.25\end{array}$} & \multirow{2}{*}{$\begin{array}{c}\begin{array}{c}\text { Standar } \\
\text { Deviasi }\end{array} \\
4.869\end{array}$} & \multirow{2}{*}{$\begin{array}{c}\begin{array}{c}\text { Mini- } \\
\text { mal-Mak- } \\
\text { simal }\end{array} \\
39-67\end{array}$} & \multirow{2}{*}{$\begin{array}{r}\mathbf{9 5 \%} \mathrm{CI} \\
51.58-52.92\end{array}$} \\
\hline $\begin{array}{l}\text { Pemanfaatan Puskes- } \\
\text { mas sebagai Gate- } \\
\text { keeper }\end{array}$ & $\begin{array}{c}\text { Pemanfaatan Puskesmas } \\
\text { sebagai gatekeeper di Dua } \\
\text { Puskesmas }\end{array}$ & & & & \\
\hline \multirow{5}{*}{$\begin{array}{l}\text { Karakteristik Peng- } \\
\text { guna Pelayanan }\end{array}$} & Umur & 47.19 & 15.078 & $19-77$ & $45.13-49.25$ \\
\hline & Pendidikan & 11.74 & 3.417 & $0-20$ & $11.28-12.21$ \\
\hline & Persepsi Sakit & 2.15 & 1.205 & $1-6$ & $1.98-2.31$ \\
\hline & Penyakit Kronis & 0.67 & 0.741 & $0-3$ & $0.57-0.77$ \\
\hline & Lama Berobat (bulan) & 106.83 & 99.946 & $3-360$ & $93.17-120.49$ \\
\hline $\begin{array}{l}\text { Persepsi Pengguna } \\
\text { Pelayanan }\end{array}$ & $\begin{array}{l}\text { Persepsi terhadap Sikap } \\
\text { Petugas Kesehatan }\end{array}$ & 51.1 & 6.404 & $31-68$ & $50.22-51.97$ \\
\hline
\end{tabular}

Tabel 2. Karakteristik (Jenis Kelamin dan Pekerjaan ) Pengguna Pelayanan di Dua Puskesmas Kota Bekasi Tahun 2016

\begin{tabular}{cccc}
\hline Variabel & & Jumlah $(\mathrm{n})$ & Persentase (\%) \\
\hline Jenis kelamin & Laki laki & 72 & 34.6 \\
& Perempuan & 136 & 65.4 \\
\multirow{3}{*}{ Pekerjaan } & Bekerja & 71 & 34.1 \\
& Tidak Bekerja & 137 & 65.9 \\
\hline Total & & 208 & 100 \\
\hline
\end{tabular}

Tabel 3. Distribusi Pemanfaatan Puskesmas sebagai Gatekeeper per Domain di Dua Puskesmas Kota Bekasi Tahun 2016

\begin{tabular}{|c|c|c|c|c|c|c|}
\hline \multicolumn{2}{|c|}{ Variabel } & Mean & $\begin{array}{l}\text { Standar } \\
\text { Deviasi }\end{array}$ & $\begin{array}{l}\text { Mini- } \\
\text { mal-Maksi- } \\
\text { mal }\end{array}$ & $95 \% \mathrm{CI}$ & $\begin{array}{l}\text { Nilai Min- } \\
\text { Mak yg } \\
\text { diharapkan }\end{array}$ \\
\hline \multirow{4}{*}{$\begin{array}{c}\text { Domain } \\
\text { Pemanfaatan } \\
\text { Puskesmas } \\
\text { sebagai Gate- } \\
\text { keeper }\end{array}$} & First Contact Care & 7.92 & 0.801 & $5-10$ & $7.81-8.03$ & $3-12$ \\
\hline & Continuity Care & 22.87 & 3.326 & $13-32$ & $22.42-23.32$ & $8-32$ \\
\hline & Coordination Care & 10.50 & 1.150 & $4-14$ & $10.35-10.65$ & $4-16$ \\
\hline & $\begin{array}{c}\text { Comprehensiveness } \\
\text { Care }\end{array}$ & 11.07 & 1.950 & $4-16$ & $10.80-11.33$ & $4-16$ \\
\hline
\end{tabular}


Tabel 4 Analisis Korelasi dan Regresi Variabel Independen dengan Pemanfaatan Puskesmas sebagai Gatekeeper di Dua Puskesmas Kota Bekasi Tahun 2016

\begin{tabular}{|c|c|c|c|c|}
\hline Variabel & $\mathbf{r}$ & $\mathbf{R}^{2}$ & Persamaan garis & P value \\
\hline Umur & 0.083 & 0.007 & $\begin{array}{l}\text { Pemanfaatan Puskesmas Sebagai Gate- } \\
\text { keeper }=50.989+0.027 \text { (umur) }\end{array}$ & 0.235 \\
\hline Pendidikan & 0.046 & 0.002 & $\begin{array}{l}\text { Pemanfaatan Puskesmas Sebagai Gate- } \\
\text { keeper }=51,473+0,066 \text { (pendidikan) }\end{array}$ & 0.506 \\
\hline Persepsi Sakit & 0.14 & 0.000 & $\begin{array}{l}\text { Pemanfaatan Puskesmas Sebagai Gate- } \\
\text { keeper }=52,127+0,057 \text { (persepsi sakit) }\end{array}$ & 0.839 \\
\hline Penyakit Kronis & 0.036 & 0.001 & $\begin{array}{l}\text { Pemanfaatan Puskesmas Sebagai Gate- } \\
\text { keeper }=52,090+0,237 \text { (penyakit kronis) }\end{array}$ & 0.604 \\
\hline $\begin{array}{l}\text { Persepsi terhadap } \\
\text { Sikap Petugas } \\
\text { Kesehatan }\end{array}$ & 0.720 & 0.519 & $\begin{array}{l}\text { Pemanfaatan Puskesmas Sebagai } \\
\text { Gatekeeper }=24,271+0,548 \text { (persepsi } \\
\text { terhadap sikap petugas kesehatan) }\end{array}$ & $0.000^{*}$ \\
\hline Lama Berobat & 0.137 & 0.019 & $\begin{array}{l}\text { Pemanfaatan Puskesmas Sebagai Gate- } \\
\text { keeper }=51,535+0,007 \text { (lama berobat) }\end{array}$ & $0.048^{\star}$ \\
\hline
\end{tabular}

* = bermakna signifikan secara statistik ( $\mathrm{p}$-value $<0,05)$

Tabel 5 Analiss t-test Variabel Jenis Kelamin dan Pekerjaan dengan Pemanfaatan Puskesmas Sebagai Gatekeeper Tahun 2016

\begin{tabular}{cccccc}
\hline Variabel & $\mathrm{N}$ & Mean & SD & SE & Pvalue \\
\hline Jenis Kelamin & & & & & \\
Laki-laki & 72 & 52.60 & 4.912 & 0.579 & 0.456 \\
Perempuan & 136 & 52.07 & 4.854 & 0.416 & \\
Pekerjaan & & & & & \\
Bekerja & 71 & 51.14 & 4.746 & 0.563 & $0.018^{*}$ \\
Tidak Bekerja & 137 & 52.82 & 4.849 & 0.414 & \\
\hline
\end{tabular}

* = bermakna signifikan secara statistik $(\mathrm{p}$-value $<0,05)$

Tabel 6. Pemodelan Terakhir Multivariat

\begin{tabular}{llllll}
\hline Variabel & Koefisien B & P value & $\begin{array}{l}\text { Koefisien } \\
\text { Beta }\end{array}$ & $\mathrm{r}$ & $\mathrm{R}^{2}$ \\
\hline Pekerjaan & 0,981 & 0,048 & 0,096 & & \\
& & & & 0,727 & 0,528 \\
Persepsi terhadap sikap petugas kesehatan & 0,541 & 0,000 & 0,711 & & \\
\hline
\end{tabular}


Berdasarkan hasil uji analisis bivariat, variabel persepsi terhadap sikap petugas kesehatan, pekerjaan dan lama berobat menunjukan hubungan dengan pemanfaatan puskesmas sebagai gatekeeper (Tabel 4 dan 5). Variabel yang memiliki $\mathrm{R}^{2}$ tertinggi adalah persepsi terhadap sikap petugas kesehatan yaitu sebesar 0.519 yang berarti kemampuan persepsi terhadap sikap petugas kesehatan untuk memprediksi pemanfaatan Puskesmas sebagai gatekeeper sebesar $51.9 \%$ dan memiliki hubungan yang kuat $(\mathrm{r}=0.720)$.

Berdasarkan tabel 6 terdapat dua variabel yang berhubungan dengan pemanfaatan Puskesmas sebagai gatekeeper di dua Puskesmas Kota Bekasi yaitu pekerjaan dan persepsi terhadap sikap petugas kesehatan. Selanjutnya dilakukan uji asumsi terhadap model tersebut dan hasilnya semua asumsi terpenuhi. Dari pemodelan terakhir terlihat bahwa variabel yang paling besar pengaruhnya terhadap pemanfaatan Puskesmas sebagai gatekeeper di dua Puskesmas Kota Bekasi adalah persepsi terhadap sikap petugas kesehatan (koefisien beta $=0.711$ ). Berdasarkan koofisien B masing-masing variabel independen pada pemodelan terakhir multivariat didapatkan persamaan regresi sebagai berikut:

Fungsi gatekeeper $=23,984+0,981$ pekerjaan + 0,541 Persepsi terhadap sikap petugas kesehatan

Dengan model persamaan ini, penulis dapat memperkirakan pemanfaatan puskesmas sebagai gatekeeper di dua Puskesmas Kota Bekasi dengan menggunakan variabel pekerjaan dan persepsi terhadap sikap petugas kesehatan. Adapun arti koef. $B$ untuk masing-masing variabel independen yaitu: (1) Variabel pekerjaan sebesar 0,981 artinya setiap responden yang tidak bekerja akan meningkatkan skor pemanfaatan puskesmas sebagai gatekeeper sebesar 0,981 dan (2) Variabel persepsi terhadap sikap petugas kesehatan sebesar 0,541 artinya setiap kenaikan 1 poin skor persepsi terhadap sikap petugas kesehatan akan meningkatkan skor pemanfaatan puskesmas sebagai gatekeeper sebesar 0,541.

Koefisien Beta digunakan untuk mengetahui variabel mana yang paling besar pengaruhnya dalam menentukan variabel dependen (pemanfaatan Puskesmas sebagai gatekeeper). Semakin besar koefisien Beta berarti semakin besar pengaruhnya terhadap variabel dependen. Berdasarkan hasil di atas, variabel yang paling dominan mempengaruhi pemanfaatan puskesmas sebagai gatekeeper adalah persepsi terhadap sikap petugas kesehatan (koefisien Beta $=$ $0.711)$.

\section{Pembahasan}

Konsep pelayanan kesehatan primer pada era Jaminan Kesehatan Nasional (JKN) dikembangkan dengan optimalisasi peran pelayanan primer sebagai gatekeeper (BPJSa, 2014). Berdasarkan hasil penelitian, rata-rata skor pemanfaatan Puskesmas sebagai gatekeeper di dua puskesmas Kota Bekasi Tahun 2016 sebesar 52,25. Jika dilihat dari skor minimal 19 dan maksimal 76, maka hasil 52,25 masuk dalam kategori cukup. Namun angka rujukan di dua puskesmas masih tinggi, yakni di atas 15\%. Hal ini menunjukkan pemanfaatan puskesmas sebagai gatekeeper masih belum optimal.

Hasil analisis menunjukkan bahwa tidak ada hubungan antara jenis kelamin dengan pemanfaatan puskesmas sebagai gatekeeper. Puskesmas memberikan pelayanan yang sama tanpa membedakan jenis kelamin sehingga perbedaan skor antara responden laki-laki $(52,60)$ dan responden perempuan $(52,07)$ hanya sedikit. Hasil ini sejalan dengan penelitian Yuliawati (2002) menemukan bahwa tidak terdapat perbedaan jenis kelamin terhadap keputusan untuk mencari perawatan kesehatan.

Rata-rata umur pengguna pelayanan di dua puskesmas Bekasi adalah 47,19 tahun dan tergolong kategori lansia (Depkes, 2003). Hasil penelitian menunjukkan tidak ada hubungan antara umur dengan pemanfaatan puskesmas sebagai gatekeeper. Menurut penelitian Maryam (2008), kesadaran lansia untuk ikut serta dalam Jaminan Kesehatan Nasional dikaitkan dengan beberapa hal diantaranya yaitu usia lansia merupakan usia rentan terhadap penyakit kronis, usia dimana produktivitas menurun dan kekebalan tubuh menurun. Hasil penelitian ini berbeda dengan penelitian Wong et al,. (2010), dengan menggunakan Primary Care Assessment Tool (PCAT) didapatkan hasil umur tua (lansia) mempunyai skor yang rendah pada domain koordinasi dan akses pelayanan kesehatan dibandingkan kelompok usia lainnya.

Hasil analisis menyebutkan bahwa tidak ada hubungan antara pendidikan dengan pemanfaatan puskesmas sebagai gatekeeper. Hal ini sesuai dengan penelitian Januarizal (2008) dan Madunde, dkk (2013) yang menunjukkan bahwa tidak ada hubungan pendidikan dengan pemanfaatan pelayanan kesehatan rawat jalan. Menurut Zchock (1979), tingkat pendidikan mempengaruhi tingkat utilisasi pelayanan kesehatan. Orang dengan tingkat pendidikan formal lebih tinggi akan mempunyai tingkat pengetahuan akan informasi tentang pelayanan kesehatan yang lebih baik dan pada akhirnya akan mem- 
pengaruhi status kesehatan seseorang.

Berdasarkan hasil analisis, disebutkan bahwa ada hubungan antara pekerjaan dengan pemanfaatan puskesmas sebagai gatekeeper. Hal ini mungkin disebabkan karena responden yang bekerja agak sulit mengakses pelayanan puskesmas dikarenakan jam operasional yang bersamaan dengan jam kerja. Dalam penelitian ini lebih banyak responden yang tidak bekerja yang mengakses Puskesmas (65.9\%). Berdasarkan hasil penelitian dari Su'udi (2010) sebanyak 32 responden (7.9\%) menyatakan jam buka puskesmas belum sesuai dengan kebutuhan waktu untuk berobat.

Dari hasil analisis diketahui bahwa tidak ada hubungan antara persepsi sakit dengan pemanfaatan Puskesmas sebagai gatekeeper. Hal ini dapat disebabkan karena tingkat keparahan (severity) yang berbeda-beda pada tiap individu. Dalam Behavioral Model Anderson (1975) dalam Ilyas (2006), persepsi sakit dan diagnosa penyakit merupakan karakteristik kebutuhan (need characteristics) yang menjadi determinan pemanfaatan pelayanan kesehatan.

Hasil penelitian menunjukkan rata-rata penyakit kronis yang diderita responden adalah 0.67, dengan jumlah responden yang tidak didiagnosa penyakit kronis sebanyak 100 orang $(48,1 \%)$ dan yang didiagnosa penyakit kronis sebanyak 108 orang (51.9\%). Dari analisis bivariat dilakukan didapatkan tidak ada hubungan antara penyakit kronis dengan pemanfaatan Puskesmas sebagai gatekepeer. Berbeda dengan hasil penelitian Su'udi (2010) yaitu adanya penyakit yang diderita memberikan peluang memanfaatkan pelayanan kesehatan Puskesmas 2 kali lebih besar dibandingkan kelompok yang tidak ada penyakit.

Rata-rata skor persepsi terhadap sikap petugas kesehatan adalah 51.10 dengan skor minimal yang ditentukan adalah 17 dan maksimal adalah 68, maka dikategorikan cukup. Dari hasil analisis yang dilakukan didapatkan hasil bahwa ada hubungan antara persepsi terhadap sikap petugas kesehatan dengan pemanfaatan puskesmas sebagai gatekepeer. Kualitas pelayanan kesehatan bersifat multidimensi dan jika ditinjau dari pemakai jasa pelayanan kesehatan (health consumer) maka pengertian kualitas lebih terkait pada ketanggapan petugas memenuhi kebutuhan pasien, kelancaran komunikasi antara petugas dengan pasien, keprihatinan serta keramahtamahan petugas dalam melayani pasien, kerendahan hati dan kesungguhan (Robert \& Prevest, dalam Lupiyoadi, 2001).

Dari hasil analisis yang dilakukan didapatkan ha- sil bahwa ada hubungan antara lama berobat dengan pemanfaatan Puskesmas sebagai gatekepeer. Pelayanan kesehatan yang biasa diakses berhubungan dengan kemungkinan yang lebih tinggi untuk mencari pengobatan dan meningkatkan jumlah kunjungan ke pelayanan kesehatan (Hong Le, 2009).

Hasil penelitian menunjukkan rata-rata lama berobat responden penggguna pelayanan Puskesmas sebagai gatekepeer adalah 106.83 bulan (8.9 tahun). Jika dilihat dari kategori lama berobat dimana sebanyak 62 responden (29.8\%) mempunyai lama berobat $<36$ bulan (kurang dari 3 tahun) dengan skor fungsi gatekepeer 50.42, sebanyak 48 responden (23\%) mempunyai lama berobat antara 36 bulan ( 3 tahun) sampai dengan 60 bulan ( 5 tahun) dengan skor fungsi gatekeeper 53.46 dan sebanyak 98 responden (47.1\%) mempunyai lama berobat > 60 bulan (lebih dari 5 tahun) dengan skor gatekepeer 52.91, maka semakin lama berobat ke Puskesmas semakin bagus skor fungsi gatekeeper. Hal ini karena menunjukkan semakin lama menjadi pasien di puskesmas tersebut, penilaian terhadap puskesmas baik kepada sikap petugas kesehatan dan fungsi puskesmas sebagai gatekepeer menjadi baik.

Hasil uji multivariat menunjukkan bahwa dua variabel yang berhubungan signifikan dengan pemanfaatan puskesmas sebagai gatekeeper di dua puskesmas Kota Bekasi, yaitu pekerjaan dan persepsi terhadap sikap petugas kesehatan. Dari kedua variabel tersebut, variabel persepsi terhadap sikap petugas kesehatan merupakan faktor yang paling dominan dalam memprediksi pemanfaatan puskesmas sebagai gatekeeper di dua puskesmas Kota Bekasi.

Menurut Gibson dkk (1996), persepsi merupakan suatu proses dalam diri seseorang dalam memahami keadaan atau situasi di lingkungannya yang melibatkan pengorganisasian dan penafsiran sebagai suatu rangsangan dalam suatu pengalaman psikologis. Pada penelitian ini, persepsi terhadap sikap petugas kesehatan mempunyai hubungan yang kuat dengan pemanfaatan Puskesmas sebagai gatekeeper $(\mathrm{r}=0.720)$. Komunikasi dan sikap petugas kesehatan yang baik akan menimbulkan persepsi yang positif dan mendukung pasien untuk menerima tindakan yang diberikan. Persepsi masyarakat terhadap pelayanan yang baik dari puskesmas memberikan kesan yang mendalam dan menimbulkan motivasi untuk dapat memanfaatkan layanan kesehatan yang diberikan. Apabila masyarakat mengetahui bahwa penyelenggaraan pelayanan sesuai dengan yang diharapkan maka kepercayaan dan kepuasan akan semakin meningkat (Wijono, 2010). 


\section{Kesimpulan dan Saran}

\section{Kesimpulan}

Pemanfaatan Puskesmas sebagai gatekeeper di dua puskesmas Kota Bekasi masih belum optimal. Variabel yang berhubungan dengan pemanfaatan puskesmas sebagai gatekeeper adalah pekerjaan, persepsi terhadap sikap petugas kesehatan, dan lama berobat. Sikap petugas kesehatan menjadi faktor dominan dimana akan mempengaruhi pemanfaatan kembali pelayanan kesehatan di puskesmas tersebut, sehingga sikap baik perlu dimiliki oleh petugas kesehatan dan menjadi perhatian menuju pelayanan kesehatan prima. Selain itu, persepsi yang baik terhadap sikap petugas kesehatan akan mempengaruhi kontinuitas layanan sehingga pasien akan selalu ke puskesmas tersebut ketika ada keluhan sakit. Hal ini terkait dengan variabel lama berobat yaitu loyalitas pasien terhadap pemanfaatan layanan kesehatan.

\section{Saran}

Perlu dilakukan sosialisasi terus menerus agar pasien lebih paham dengan prosedur rujukan. Selain itu, diperlukan kelengkapan fasilitas penunjang dan obat-obatan agar pemeriksaan pasien di puskesmas lebih maksimal. Sikap petugas kesehatan menjadi hal yang penting untuk meningkatkan pemanfaatan pelayanan di puskesmas. Evaluasi yang dilakukan oleh BPJS seharusnya tidak hanya berdasarkan angka kunjungan dan angka rujukan, namun juga dilihat dari penerapan konsep gatekeeper secara keseluruhan karena otomatis akan mengurangi angka rujukan dan tidak membebani FKTL. Penelitian selanjutnya juga perlu dilakukan untuk mengetahui kendala penyedia pelayanan primer dalam menjalankan fungsi gatekeeper.

\section{Daftar Pustaka}

BPJS Kesehatan. 2014a. Panduan Praktis Gate Keeper Concept Faskes BPJS Kesehatan. Jakarta

BPJS Kesehatan. 2014b. Panduan Praktis Sistem Rujukan Berjenjang. Jakarta

Gibson, J.L., J.M. Ivancevich, J.H. Donnelly, Jr., 1996, Organisasi, Perilaku, Struktur, Proses. Jakarta: Bina Rupa Aksara.

Ilyas, Jaslis. 2006. Mengenal Asuransi Kesehatan Review Utilisasi Manajemen Klaim dan Fraud. Depok; CV. Usaha Prima, Cetakan Kedua Maret 2006.

Kemenkes RI. 2014a. Peraturan Menteri Kesehatan RI nomer 75 Tahun 2014 Tentang Pusat Kesehatan Masyarakat.

Kemenkes RI. 2014b. Peraturan Menteri Kesehatan No. 28 Tahun 2014 tentang Jaminan Kesehatan
Nasional.

Lee, J. H., Choi, Y.-J., Sung, N. J., Kim, S. Y., Chung, S. H., Kim, J., Jeon, T.-H. \& Park, H. K. 2009. Development of the Korean primary care assessment tool-measuring user experience: tests of data quality and measurement performance. International Journal for Quality in Health Care, 21, 103-111.

Le, P. H. 2009. An empirical model to estimate the demand for primary care in urban settings. 1463619 M.P.H., The University of Texas School of Public Health.

Lupiyoadi, Rambar. 2011. Manajemen Pemasaran Edisi kesebelas. Jakarta: Salemba Empat.

Peraturan Presiden No. 12 Tahun 2013 tentang Jaminan Kesehatan Nasional. Diakses 4.2.2016

Parasuraman, Zeithaml, Valerie A., Berry, Leonard.L,. 1988. SERVQUAL: Multiple-Item Scale for Measuring Consumer Perceptions of Service Quality.

Starfield, Barbara. 1994. Is primary care essential? The Lancet, 344, 1129-1133.

Saurina, C., Vall-Ilosera, L. \& Saez, M. 2012. Factors Determining Access to and Use of Primary Health Care Service in the Girona Health Region (Spain). Springer.

Shi, L., Starfield, B., Xu, J., Politzer, R. \& Regan, J. 2003. Primary Care Quality: Community Health Center and Health Maintenance Organization. Southern Medical Journal, 96.

Su'udi, Ahmad. 2010. Analisis Pemanfaatan Subsidi Pelayanan Kesehatan Gratis Tingkat Puskesmas di Kabupaten Tabalong Kalimantan Selatan Tahun 2010. Tesis. Depok. Fakultas Kesehatan Masyarakat.diakses 20.4.2015

Tsai, J., Shi, L., Yu, W.-L., Hung, L.-M. \& Lebrun, L. A. 2010. Physician Specialty and The Quality of Medical Care Experiences in the Context of the Taiwan National Health Insurance System. JAB$F M, 23$.

Thom, D. H., MD.PhD, Ribisil, K. M., PhD, Stewert, A. L. P., \& Luke, D. A. P. 1999. Further Validation and Reliability Testing of the Trust in Physician Scale 37, 510-517.

Wijono, Sutarto. 2010. Psikologi Inustri dan Organisasi. Kencana : Jakarta.

World Health Organization (WHO). 2008. The World Health Report 2008: Primary Health Care - Now More Than Ever.

Wong, S. Y., Kung, Y., Griffiths, S. M., Carthy, T., Wong, M. C., LO, S. V., Chung, V. C., Goggins, W. B. \& Starfield, B. 2010. Comparison of Primary Care Experiences among Adults in General 
Outpatient Clinics and Private General Practice Clinics in Hong Kong. BMC Public Health.

Yang, H., Shi, L., Lebrun, L. A., Zhou, X., Liu, J. \& Wang, H. 2012. Development of the Chinese primary care assessment tool: data quality and measurement properties. International Journal for Quality in Health Care.
Yustianto, Johan. 2009. Analisis Kualitas Pelayanan Kesehatan Studi Kasus Pusat Kesehatan Masyarakat (Puskesmas) Kecamatan Gambir Jakarta Pusat. Tesis. FISIP UI 